\title{
A MULTI-OBJECTIVE COURSE SCHEDULING MODEL: COMBINING FACULTY PREFERENCES FOR COURSES AND TIMES
}

\author{
Masood A. Badri ${ }^{1} \uparrow \ddagger$, Donald L. Davis ${ }^{2} \S$, Donna F. Davis ${ }^{2} \llbracket$ and John Hollingsworth ${ }^{3} \|$ \\ ${ }^{1}$ School of Business, University of United Arab Emirates, P.O. Box 17555, Al-Ain, United Arab Emirates \\ ${ }^{2}$ College of Business Administration, The University of Southern Mississippi, Mississippi, U.S.A. \\ ${ }^{3}$ CUNY, College of Staten Island, New York, U.S.A.
}

(Received June 1996; in revised form July 1997)

\begin{abstract}
Scope and Purpose - The purpose of this paper is to present an application of goal programming as an aid in faculty-course-time assignments. The model examines the conflicting objectives of departmental policies with regard to course offerings with those of faculty-course and course-time preferences. The formulated model has a distinct advantage over the original proposed by Schniederjans and Kim (1987) and the extended version proposed by Badri (1996). The model can simultaneously consider faculty preferences for courses and for times. The model is applied in a real-world setting, and implementation results are discussed.
\end{abstract}

\begin{abstract}
This paper formulates a multi objective zero-one course scheduling model. Through an optimization procedure, the model seeks to maximize faculty preferences to courses and times. The model seeks to assign faculty members to courses and to allocate courses to time-blocks simultaneously. The core of the procedure is formed by a matrix, with rows divided into three sections indicating course priorities (first priority in the first line, second priority in the second line, and third priority in the third line); and with letters indicating priorities for a specific time-block ("a" for first choice, "b" for second choice, and "ce" for third choice). The paper then describes application of the model to the Department of Statistics, College of Business and Economics at the United Arab Emirates University. The results of the application demonstrate the model's capability to provide an assignment that satisfies departmental policies and procedures with regard to course offerings, as well as recognizing the personal preferences of the faculty for teaching particular courses during certain time-blocks. $\mathbb{C}$ 1998 Elsevier Science Ltd. All rights reserved
\end{abstract}

\section{INTRODUCTION}

A periodic problem (each quarter or semester) for academic departments is the assignment of courses to faculty members and then, the assignment of these courses to time slots. These are important administrative tasks that must be performed in academic departments each semester. In such an academic environment, there exist some organizational, as well as individual goals that influence the assignment problem. The goals of administrators are determined by changes in student demand for courses, and hence, the desire of involved administrators to provide such necessary courses. In addition, these course offerings have to meet contractual agreements on faculty teaching loads. Of course, there can also exist considerable latitude in assigning faculty members to specific courses during a particular semester. Other factors influencing the assignment problem might have to do with limited resources, such as the number of time slots available for scheduling, and the number of classrooms available during a certain time.

† To whom all correspondence should be addressed (email: masoodb@adminpo.uaeu.ac.ae).

‡ Masood A. Badri is an Associate Professor of Operations Management in the College of Business and Economics at the United Arab Emirates (UAE) University. He is also serving as Assistant Deputy Vice Cancellor for Academic Affairs. Dr. Badri received his Ph.D. degree from the University of Mississippi, his MBA degree from the University of San Diego, and his BS in Applied Mechanics from the University of California. Prior to entering the academic world, he served as an Engineer at UAE Minsitry of Electricity. His current research interests include mathmatical programming, simulation analysis, and neural networks.

§ Donald L. Davis is a Professor of Management Information Systems in the College of Business Administration at the University of Mississippi. He received a BA degree in Mathematics and an MBA from Florida State University. Prior to entering the educational profession, Dr. Davis served in the U.S. Army for eight years and then held several positions in indsutry. His current research interests are in use-system interfaces in DSS, expert systems and neural networks.

If Donna F. Davis is an Associate Professor of Management Information Systems and Director of Curriculum in the College of Business Administration at the University of Southern Mississippi. She received her Ph.D. degree in Management Information Systems and the M. Accountancy from the University of Mississippi, and her BS in Accounting from Florida State University. Prior to entering the acadamic community Dr. Davis spent a number of years in industry and goverment developing information systems. Her current research interests include organizational effects of information technology.

\|l John Hollingsworth is an Associate Professor of Management Information Systems at CUNY, College of Staten Island. His research interests include the organizational effects of information technology, DSS and neural networks. 
Other factors are related to policy, such as number of preparations, and allowable number of night classes [1].

An important consideration in the assignment process is the personal preferences of the faculty staff in specific course-assignments [2]. Moreover, there are some preferences with regard to teaching during certain times $[3,4]$. Some faculty members prefer to teach early in the morning, while others might prefer teaching during the evening. Nevertheless, these personal preferences should not be ignored when coming up with faculty-course-time assignments.

This type of assignment problem commonly exists in all the major departments of academic institutions. The suggested model is applied to the scheduling problem in the Department of Statistics, College of Business and Economics at the United Arab Emirates University. The department faced the usual changes in faculty assignments to courses and to time slots. These assignment problems should be solved in a way that satisfies the department's course offering goals, policies and limited resources, while allowing the faculty preferences in course and time selection.

Badri [3] designed a two-stage zero-one goal programming model, to first assign faculty to courses at the department's planning level, and second, to assign the derived faculty-course combinations to available time slots. The first stage was based on the model suggested by Schniederjans and Kim [2] with a modification to allow for the desire for minimum number of course preparations. The second stage was built around the same concept, but decision variables were changed to reflect faculty-course assignments to available time slots. A detailed application is presented to illustrate the ease of formulation and implementation of the model. The only limitation of the model was the fact that the process required two stages. As a result, extensive time and effort were needed since certain tasks had to be performed twice (two stages). These tasks included gathering the required data, entering the data into the model, and running the model.

In the current paper, a zero-one goal programming model is introduced and applied. The model provides a one-stage solution to the assignment problem introduced by Badri [3]. In addition to considering departmental goals, the model attempts to simultaneously accommodate for faculty preferences to teach certain courses and during certain time-blocks.

\section{RELATED RESEARCH}

Most modeling approaches in institutions of higher learning tend to be directed towards aggregate planning of human, financial, and physical resources in the higher levels of academic administration planning [5-8]. However, these models cannot easily be applied at the departmental level [2]. At the department level, problems such as course-faculty-time scheduling exist, and need special modeling approaches.

Some departmental level modeling techniques dealing with faculty-course assignment, required the development of complex utility functions to express faculty preferences for certain courses [4,9-11]. As noted by Shniederjans and Kim [2], the modeling efforts required, and the time necessary to develop such complex utility functions could limit their application when used on a practical re-occurring basis on departmental level in an organization of higher education.

Several mathematical programming models have been proposed for generating faculty teaching assignments. Some of these models took a linear programming form $[12,13]$. The purpose of these models was to optimize the assignment of faculty to courses subject to number of courses needed and faculty teaching load. Others suggested integer programming models to solve the problem [4,9,11], introducing other restrictions such as minimizing the number of preparations.

Others used manual methods based on logic and graphs to solve course and classroom scheduling problems in term time tabling $[14,15]$. In addition, others proposed models incorporated in a decision support system for course scheduling $[16,17]$. These authors proposed network-based decision support systems to solve academic course scheduling problems on a large-scale university level. However, the suggested approaches may not be utilized on smaller departmental levels where other criteria become more important, such as faculty preferences for certain courses or time-blocks.

Shih and Sullivan [11] proposed a two-stage scheduling process in which a multiperiod integer programming model assigned courses to faculty members in the first stage, followed by a second model that assigned the courses to time slots. The possible schedules for each faculty member were determined from the set of all possible course combination a person might reasonably teach without violating teaching-load or preparation constraints.

Goal programming may be used in some decision processes to assure least possible deviation from 
goals [18-21]. The natural conflict in the course-faculty-time assignment problems between competing individual faculty members (i.e. faculty members wanting to teach certain courses or sections at certain times), represents an ideal application of the goal conflicting resolution characteristics inherent in goal programming.

The Harwood and Lawless [4], and the Shniederjans and Kim [2] models, however, did use goal programming to examine the conflicting goals in the faculty-course assignment problem. The major drawback with the first model is that it may be very difficult to implement. They presented a multitude of criteria that are strict requirements rather than goals. As a result, these criteria add needless complication and data collection requirements to the model. On the other hand, the model by Schniederjans and Kim [2] sought to overcome possible implementation limitations of the Harwood and Lawless model. In addition to satisfying departmental goals on the number and types of course offerings required, as well as the faculty teaching load requirements, their proposed model also dealt with faculty course teaching preferences. The major drawback with this second model is that it considered only one dimension of the departmental course scheduling, the faculty-course assignment problem. The second dimension dealing with the course-time assignment problem was not dealt with.

Finally, the model presented by Badri [3] used goal programming to perform the scheduling task using two stages. In stage I, the model utilized a modification of Schniederjans and Kim's model [2] to optimize departmental preference in course assignments. In this stage, the model assigned faculty to courses while satisfying departmental goals on the number and types of course offerings required, as well as the faculty teaching load requirements. In addition, the model dealt with faculty course teaching preferences. Shniederjans and Kim's model was modified slightly by adding other constraints that attempted to minimize the number of preparations per faculty when several sections of the same course were offered. The core of the procedure in this stage was formed by a matrix, with rows indicating faculty members; columns indicating courses; and elements indicating priorities (faculty-course teaching preferences). The decision variables in this stage were presented by $X_{i l}$ values, where each $X_{i l}$ was equal to 1 , if the $i$ th faculty member was assigned to the $l$ th course; and was equal to 0 , if the $i$ th faculty member was not assigned to the $l$ th course. The result of this analysis provided the faculty-course assignments.

Results of stage I assignments (faculty-course assignments) were then used as inputs in stage II to identify the course-time assignments. The model in stage II followed the same logic suggested by Schniederjans and Kim, but sought to assign faculty members (courses) to time slots in order to satisfy departmental goals on the number and types of faculty-course assignments required, limited departmental resources (in the number of classes available during a certain time frame), as well as other departmental preferences, such as limiting the number of evening courses. The proposed model also dealt with faculty time teaching preferences. In other words, the second stage was concerned with the application of the same procedure of stage I with one exception. In the matrix, the rows indicated faculty members; the columns indicated time-blocks; and the elements indicated priorities (faculty-time preferences).

\section{THE PROPOSED MODEL}

The proposed model seeks to overcome possible implementation limitations of the Harwood and Lawless model, to deal with the course-time assignment problem that was not included in the Shniederjans and Kim model, and also to perform the analysis in one stage rather than two, as in the Badri model.

The model data is presented in a very unique and simple manner as shown in Table 1. In essence, and through a simple numbering procedure, the table provides all the information needed to set up and formulate the model. The option of variable numbering provides extreme ease, and allows persons without extensive knowledge of multi-criteria goal programming to use. In addition, this option will reduce the number of decision variables extensively and will allow the decision maker to track all assignments in a simple manner.

The core of the procedure is formed by a matrix shown in Table 1. The table shows that, for each faculty member, course preferences are given in rows. For example, if a course appears in the first row, that course has first priority. Meanwhile, if a course appears in the second row, that course is assigned second priority. It can be seen from the table that there are three rows for each course indicating three priority levels. Time-block priorities are indicated by using letters. For example, the first priority is denoted by using the letter " $a$ "; the second priority is denoted by using the letter "b"; and the third priority is denoted by using the letter "c". Again, there are three priority levels for each time-block. 


\begin{tabular}{|c|c|c|c|c|c|c|c|c|c|c|c|c|c|}
\hline 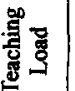 & $m$ & $m$ & $m$ & 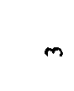 & $\sim$ & & & & $\sim$ & $m$ & $m$ & $\sim$ & \\
\hline 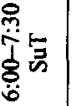 & & $\ddot{\frac{\partial}{x}}$ & $\ddot{f}$ & $\ddot{x}$ & & $\tilde{z}$ & $\dot{f}$ & & $\stackrel{\circ}{x}$ & & & 8 & - \\
\hline & & 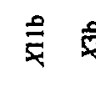 & 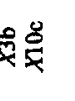 & $\dot{\vec{x}}$ & & 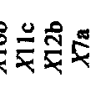 & 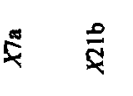 & & ฉ & 롳 & & 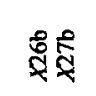 & + \\
\hline & & $\frac{m}{\bar{x}} \bar{x}$ & 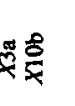 & 学 & & 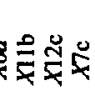 & 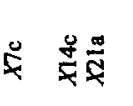 & & :̊ñ & 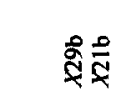 & & 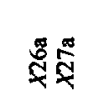 & + \\
\hline & 列 & & ğ & की & & $\frac{\pi}{\bar{x}}$ & $\frac{f}{\not}$ & & & 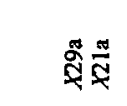 & & 总疍 & 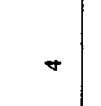 \\
\hline & 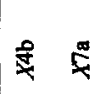 & 年 & $\ddot{\ddot{z}}$ & æึ & & $\frac{8}{8}$ & 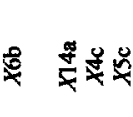 & & $\ddot{\check{x}}$ & 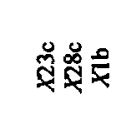 & 艾 & 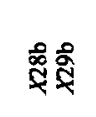 & 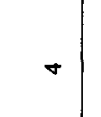 \\
\hline 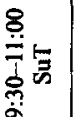 & $\stackrel{g}{\not}$ & 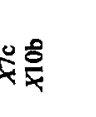 & $\stackrel{\circ}{\frac{\mathscr{g}}{x}}$ & & & $\frac{8}{8}$ & $\frac{8}{2}$ & & 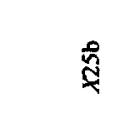 & 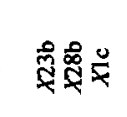 & : & 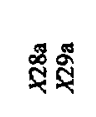 & + \\
\hline & & 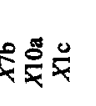 & $\frac{R}{x}$ & & & 要造 & 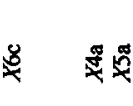 & & 䧽 & 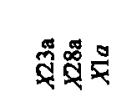 & $\stackrel{n}{2}$ & & + \\
\hline ing & $x^{\circ}$ & ฉ̊ & 号 & 8 & & & $\stackrel{\vec{z}}{\vec{x}}$ & & 承 & & 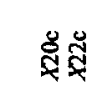 & हึ & 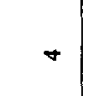 \\
\hline & คे & $\frac{2}{20}$ & $\stackrel{R}{\tilde{z}}$ & 8 & 总 & $\stackrel{8}{*}$ & $\stackrel{g}{\vec{x}}$ & & 范 & & 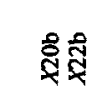 & 㖞 & + \\
\hline 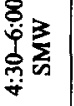 & 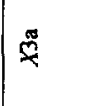 & 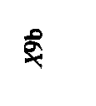 & & : & & 业 & 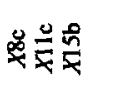 & & 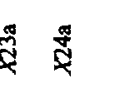 & & & 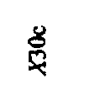 & + \\
\hline$\frac{3}{n}$ & $\check{8}$ & ฉ̊ & 孚 & 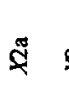 & & $\stackrel{8}{*}$ & 蛋 & & : & $\stackrel{\circ}{x}$ & & $\stackrel{\circ}{\bar{p}}$ & 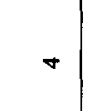 \\
\hline & 孚舜 & 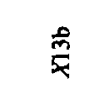 & 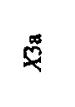 & 華 & 娄 & z & 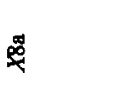 & & : & 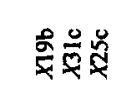 & $\stackrel{\circ}{x}$ & $\stackrel{8}{\frac{8}{5}}$ & . \\
\hline 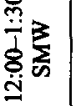 & รี & 蚝 & $\frac{8}{4}$ & & 总卷 & & $\ddot{8}$ & & 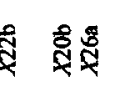 & 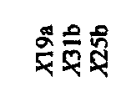 & 妾 & $\frac{\pi}{f}$ & - \\
\hline & 8 & 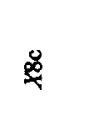 & $\frac{8}{8}$ & & 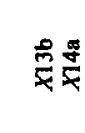 & & 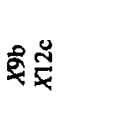 & & वृ & 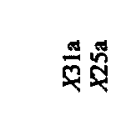 & $\stackrel{m}{\tilde{m}}$ & & . \\
\hline & $\ddot{x}$ & 总華 & 跎量 & & 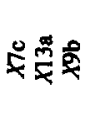 & & 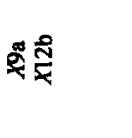 & & : & 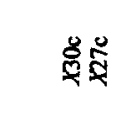 & 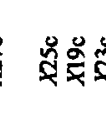 & & + \\
\hline & 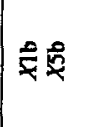 & జx & & $\stackrel{s}{x}$ & \& & s & 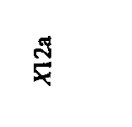 & & 蛹 & క్శ్ & รُ & & 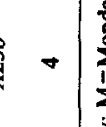 \\
\hline & चूच & ฐ & $\frac{q}{z}$ & 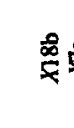 & $\stackrel{8}{\not}$ & & & & 送 & 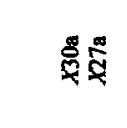 & جุ & & - \\
\hline & $g$ & 胥 & & & & & & & & & & & \\
\hline
\end{tabular}




\subsection{Variables, constants and notations}

$i$ denoting faculty (faculty number).

$j$ denoting courses (course number).

$k$ denoting time slot or block (time-block number).

$n=$ total number of faculty to assign.

$m=$ total number of courses to assign.

$o=$ total number of time-blocks to be assigned.

$c_{k}=$ total number of courses permitted within the kth time.

$q_{1}=$ total number of ranks used by faculty to define their course preferences.

$q_{z_{1}}=$ number of courses (or sections) permitted within the same $z_{1}$ th ranking.

$s_{j}=$ number of sections of each of the jth course to be offered in the semester.

$t_{i}=$ teaching load (in courses) for each ith faculty member.

$w_{z_{1}}=$ ranked weight given by faculty on the preference to be assigned to each specific course.

$w_{z_{2}}=$ ranked weight given by faculty on the preference to be assigned to teach during a specific time-block.

$d_{j}^{s+}, d_{j}^{s-}=$ positive and negative deviation from the $j$ th course offering.

$d_{i}^{t+}, d_{i}^{t-}=$ positive and negative deviation from the teaching load for the $i$ th faculty member.

$d_{k}^{c^{+}}, d_{k}^{c^{-}}=$=positive and negative deviation from the total number of classes for the $k$ th time-block.

$d_{z_{1}}^{g^{+}}, d_{z_{1}}^{g^{-}}=$positive and negative deviation from the number of course section offerings at the same faculty assigned $z_{1}$ th preference level for courses.

$d_{z_{2}}^{+}, d_{z_{2}}^{-}=$positive and negative deviation for the number of course section offerings at the same faculty assigned $z_{2}$ th preference level for the time-block.

$X_{i j k}=1$, if the $i$ th faculty to teach the $j$ th course during the $k$ th time slot, and 0 otherwise.

\subsection{Constraints}

Constraints could be grouped in seven categories. The first category of constraints represent a set of goals that need to be satisfied to ensure that all required courses are offered (or assigned). The right-handside, $s_{j}$, indicates the total number of sections of course $j$ :

$$
\sum_{i=1}^{n} \sum_{k=1}^{o} X_{i j k}+d_{j}^{s-}-d_{j}^{s+}=s_{j}(\text { for } j=1,2,3, \ldots, m) .
$$

The number of constraints representing (1) will equal the number of courses to be assigned. Again, we should note that $j$ could represent the number of courses or the number of sections to be offered.

The second set of constraints represents available teaching loads for each faculty member. As a result, one constraint is provided for each faculty member. We should note in Table 1 that rows represent faculty. The right-hand-side $t_{i}$ will equal the teaching load for each faculty member:

$$
\sum_{j=1}^{n} \sum_{k=1}^{o} X_{i j k}+d_{i}^{t-}-d_{i}^{i+}=t_{i}(\text { for } i=1,2,3, \ldots, n) \text {. }
$$

The third set of constraints reflects the limited number of resources in terms of the available number of classrooms per time-block. The right-hand-side " $c_{k}$ " reflects the number of sections that could be scheduled per time period. Hence, one constraint is needed for each time period (in Table 1, time periods are represented by columns). (3) may be set up also as a "hard" constraint, incase additional classrooms are not available:

$$
\sum_{i=1}^{n} \sum_{j=1}^{m} X_{i j k}+d_{k}^{c-}-d_{i}^{c+}=c_{k}(\text { for } k=1,2,3, \ldots, o) \text {. }
$$

The fourth set of constraints represents the faculty preferences for courses. The right-hand-side value seeks to restrict the assignment of the courses to those chosen by the faculty at the highest priority first. The same weighting system utilized by Badri [3], and Schniederjans and Kim [2] is used to reflect the faculty priority for courses. The weighting system is used as constraints and is reflected in the objective function. We use three different ranks, and hence, three goal constraints are necessary to model the faculty preferences for courses. For the first constraint, the only decision variables that are included are those that were given a rank of one (in Table 1, all courses that are assigned the rank of one are those that are shown in row one). (4) represents faculty-course preferences: 


$$
\sum_{i=1}^{n} \sum_{j=1}^{m} \sum_{k=1}^{o} X_{i j k}+d_{z_{i}}^{g-}-d_{z_{1}}^{g+}=g_{z_{1}}\left(\text { for } z_{1}=1,2,3, \ldots, q_{1}\right)
$$

Faculty preferences for time are represented by (5), where the right-hand-side will seek to maximize the assignment of the preferred (or highest priority) "time-blocks". Again, we will use a weighting system in the objective function to reflect preferences for time-blocks. Since three ranks are used, three goal constraints are necessary to model the faculty preferences for time-blocks:

$$
\left.\sum_{i=1}^{n} \sum_{j=1}^{m} \sum_{k=1}^{o} X_{i j k}+d_{z_{2}}^{-}-d_{z_{2}}^{+}=e_{z_{2}} \text { (for } z_{2}=1,2,3, \ldots, q_{2}\right) \text {. }
$$

(6) is a set of system constraints that will assure that an $X_{i j k}$ is not split. In other words, since each faculty member was given the opportunity to provide different preferences for courses and time slots. These system constraints assure that only one of these preferences is selected for each combination. The number of these constraints will equal the number of faculty-course-time combinations.

$$
\sum_{i=1}^{n} \sum_{k=1}^{o} X_{i j k} \leq 1(\text { for } j=1,2,3, \ldots, m) \text {. }
$$

(7) is a set of system constraints that will assure that for a certain faculty member during a certain timeblock, only one course is assigned. The number of these constraints will equal the number of times a certain faculty member has assigned more than one course to be scheduled during the same time-block.

$$
\sum_{j=1}^{m} X_{i j k} \leq 1(\text { for } i=1,2,3, \ldots, n ; \text { for } k=1,2,3, \ldots, o) \text {. }
$$

\subsection{Objective function}

The objective function in (8), has five priorities:

$$
\begin{aligned}
\operatorname{minimize} & Z=P_{1} \sum_{j=1}^{n}\left(d_{j}^{s+}+d_{j}^{s-}+P_{2} \sum_{i=1}^{m}\left(d_{i}^{i+}+d_{i}^{t-}\right)+P_{3} \sum_{k=1}^{o}\left(d_{k}^{c+}+d_{k}^{c-}\right)+P_{4} \sum_{z_{1}=1}^{q_{1}} w_{z_{1}}\left(d_{z_{1}}^{g+}+d_{z_{1}}^{g-}\right)\right. \\
& +P_{5} \sum_{z_{2}}^{g_{2}} w_{z_{2}}\left(d_{z_{2}}^{+}+d_{z_{2}}^{-}\right) .
\end{aligned}
$$

The first priority, $P_{1}$ in (7) is designed to satisfy the required course scheduling. By including the deviation variables, it is possible to identify any variations (under or over) that might occur. If variations occur (i.e., all courses are not assigned), the chairman has the responsibility to modify the problem (i.e., increase the teaching load of selected faculty). In the case of the United Arab Emirates University, when all classes could not be assigned, visiting professors are called for. The model seeks to exact the number of courses $s_{j}$ to be offered.

The second priority $P_{2}$, represents the teaching load requirements for each faculty member. The model seeks the exact number of teaching loads $t_{i}$ for each faculty member. The possibility of teaching load variations (i.e. more than or less than the specific $t_{i}$ ) can be easily included in the model by dropping the appropriate $d_{i}^{t^{+}}$or $d_{i}^{t-}$ variable from the objective function.

The third priority, $P_{3}$ represents the set of limited number of classrooms for each time slot goals. The model, as represented, allows for different number of classrooms to be available during different time slots. If the user of the model wants to allow only under-achievement of this goal, over-achievement deviational variable may be dropped from the objective function.

Faculty preferences for certain courses are placed at the fourth priority $\left(P_{4}\right)$. The model permits the faculty to establish the number of ranks used to express their preferences with regard to a certain course. On the other hand, the model also permits the departmental chairperson to establish these number of ranks since some courses might need fixed time slots each semester.

The number of ranks defines $q_{1}$ and $w_{z_{2}}$. Each of the $q_{1}$ goal constraints only includes decision variables that were attached to the specific ranks established by the faculty. In other words, one goal constraint is used to model all the faculty-course combinations with a rank of (Three), a second goal constraint is used to model all of the courses with a rank of (Two), and so on. The mathematical weights $w_{z_{2}}$ used to differentiate the deviational variables in the objective function in (7), are simply the reversed order of the faculty rankings. As a result, the decision variables placed in the goal constraint with a rank of (One), receives the most desirable mathematical weight of $g$ for that goal constraint's deviational variables. The 
variables with a rank of (Two) would receive a weight of $\left(q_{1}-1\right)$, and so on. The logic for the fifth priority, preferences for certain time-blocks, follows the same concept as in the fourth priority.

Other objectives considered by others, i.e. [3], could also be easily incorporated in the model. For example, the model could limit the number of allowable evening classes for each faculty member by setting the right-hand-side value to equal the maximum number of evening classes for those faculty members (or for certain classes). As a result, one equation containing the sum of all specified courses is used for those faculty members who specify more than the allowable number of evening classes.

\section{APPLICATION}

The objective of the goal programming model is to obtain an optimal faculty-course to time solution that will consider the departmental needs, policies, and resources, while satisfying faculty time preferences. To illustrate the usefulness of the proposed goal-programming model, it will be applied to a departmental assignment problem at the United Arab Emirates University. The information used in this application was obtained for the first semester of the academic year 1996/1997. The department used in this study utilizes only full-time faculty to staff their course offerings. The model allows the use of parttime faculty through the adjustment of the faculty teaching load. The department has a policy of setting fixed times for some of the courses, especially, college core courses. It should be mentioned that courses of this nature were not included in the model since the faculty-course-time assignment has already been made. Of course, the model could accommodate such a desire by simply introducing $X_{i j k}$ variables to equal one for those courses that are already pre-assigned. In other words, if the department chair requires some courses to be offered during fixed time-blocks (i.e., college core courses), the model can easily accommodate that by fixing some of the $X_{i j k}$ values as required. The department chairperson had a total of twelve full-time faculty members. The involved faculty members were asked to rank their preferences in teaching certain courses the department was expected to offer to college students. The faculty members were also required to rank their preferences with regard to time for teaching these selected courses. As discussed earlier, four goals were involved in this stage.

As shown in Table 1, courses are offered on Saturdays, Sundays, Mondays, Tuesdays, and Wednesdays only, where Thursdays and Fridays are considered weekends. The first faculty member's choice for a certain course is represented by the first line of each row. For example, faculty number one prefers, as his first choice, to teach course labeled $X_{1}$. Faculty number three prefers teaching the course labeled seventeen as his second choice. With regard to his time preference for teaching this course, he prefers teaching it on Saturdays, Mondays and Wednesdays, at 4:30 as his first choice, at 6:00 as his second choice, and at 7:30 as his last choice.

\subsection{Model translation}

The data in Table 1 could easily be translated into formulas to be solved using goal programming. However, the chairman of the department acknowledged his reservations with regard to the complexity of the structure of data in the table. As a result, we presented the data in another form to facilitate model translation for the common user. Table 2 is a transformation of Table 1 in a much simpler form. In essence, and through a simple numbering procedure, the $X_{i j k}$ values are written in continuous numbering style. The table provides all the information needed to set up and formulate the model. However, the user is required to relate each variable appearing in Table 2 to those in Table 1. In other words, if Table 2 is used, a simple tracking of the variables is needed. The chairperson had no reservation with the presentation style in the second table. When constructing the equations (constraints), we will show that the user has the privilege to translate the data into equation forms using either table. One advantage of the model is that the maximum problem size that can be solved under the stated computational requirements depends on the linear programming software used and the memory of the personal computer. Most available LP software consider the size of the current problem as being small.

\subsection{Offer all courses}

As shown from Table 1, a total of 31 courses were required to be assigned; and from Table 2, we note that a total of 252 zero-one variables are to be solved. It is apparent that one constraint is needed for each course where the right-hand-side is set to one. We can show here that the data in both tables could be used to present the equations needed for satisfying course requirements. If data in Table 1 is used, (9) will result for satisfying the requirement of offering the first course. The equation tracked all appearances of 


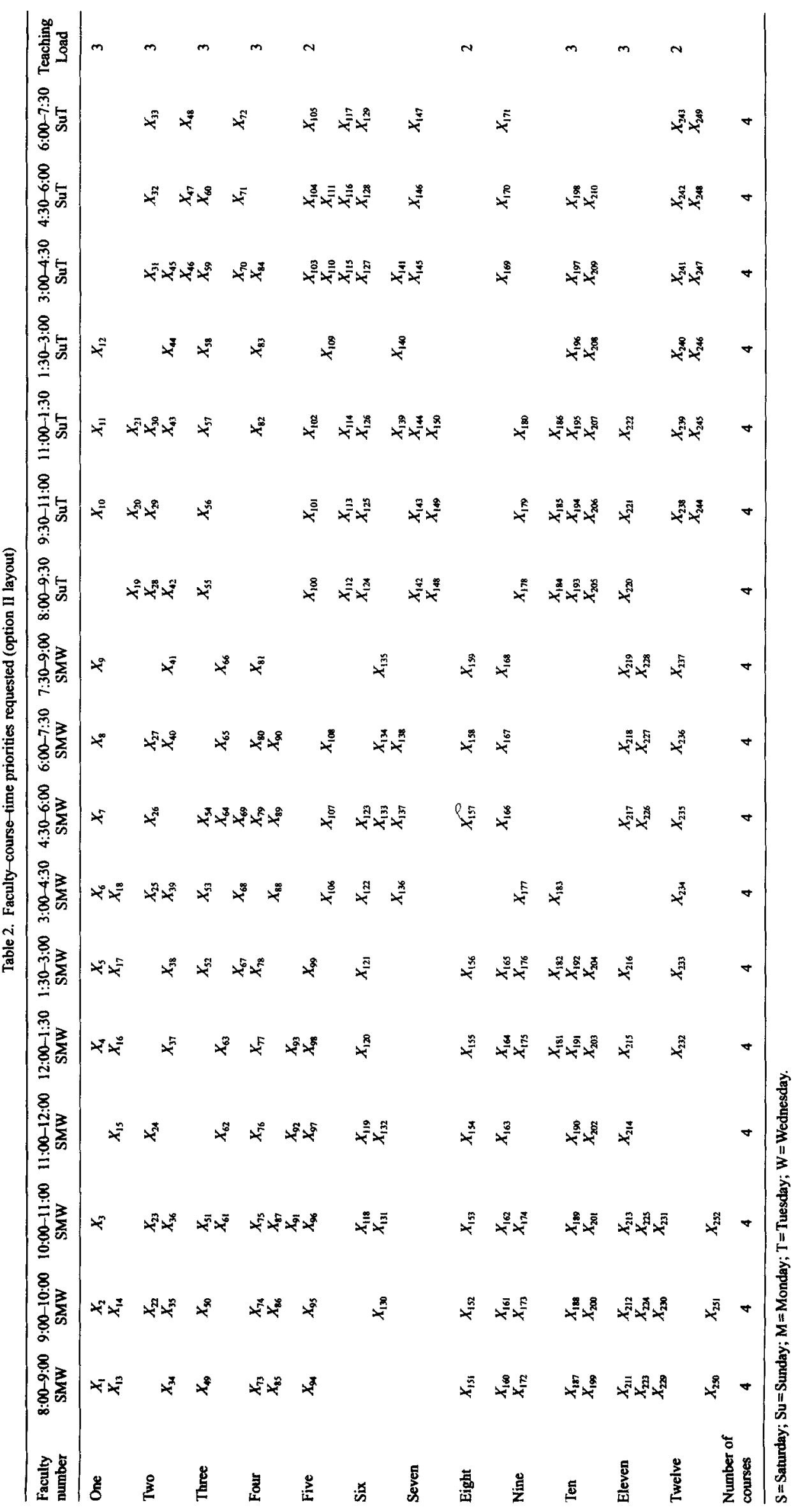


the first course in the table. For example, $X_{1,1,1}$ represents faculty " 1 ", preferring course " 1 " to be taught in the number " 1 " time-block. Meanwhile, $X_{2,1,9}$ represents faculty " 2 ", preferring course " 1 ", to be taught in the number "9" time-block. On the other hand, if data in Table 2 is used, (10) will result for the offering of the first course. It is obvious that (10) is much easier to understand, comprehend, and model:

$$
\begin{gathered}
X_{1,1,1}+X_{1,1,2}+X_{1,1,3}+X_{2,1,9}+X_{2,1,10}+X_{2,1,11}+X_{3,1,1,15}+X_{3,1,16}+X_{3,1,17}+X_{10,1,11}+X_{10,1,12}+X_{10,1,13}+d_{1}^{-}-d_{1}^{+}=1, \\
X_{1}+X_{2}+X_{3}+X_{40}+X_{41}+X_{42}+X_{70}+X_{71}+X_{72}+X_{205}+X_{206}+X_{207}+d_{1}^{-}-d_{1}^{+}=1
\end{gathered}
$$

By following the same logic as in $(9)(10)$, we can write the equations needed for the other courses. A total of 31 equations are needed to represent all the courses needed to be offered.

\subsection{Satisfy faculty teaching load}

A total of twelve faculty members are available to assign all the courses to. Hence, we need twelve constraints to ensure that the teaching load of each faculty member is satisfied. We should note that not all faculty carry the same teaching load. For example, faculty number seven is the chairman with only one course load to carry. Again, we could use the notations presented in either Table 1 or Table 2 to write the constraints necessary. (11)(12) present the constraints using the two notations for the first faculty:

$$
\begin{aligned}
& X_{1,1,1}+X_{1,1,2}+X_{1,1,3,3}+X_{1,2,5}+X_{1,2,6}+X_{1,2,7}+X_{1,3,8}+X_{3,1.9}+X_{1,3,10}+X_{1,4,12}+X_{1,4,13}+X_{1,4,14}+X_{1,5,1}+X_{1,5,2}+X_{1,6,4}+X_{1,6.5} \\
&+X_{1,6,6}+X_{1,6,7}+X_{1,7,11}+X_{1,7,12}+X_{1,7,13}+d_{32}^{-}-d_{32}^{+}=3, \\
& X_{1}+X_{2}+X_{3}+X_{4}+X_{5}+X_{6}+X_{7}+X_{8}+X_{9}+X_{10}+X_{11}+X_{12}+X_{13}+X_{14}+X_{15}+X_{16}+X_{17}+X_{18}+X_{19}+X_{20}+X_{21}+d_{32}^{-} \\
&-d_{32}^{+}=3 .
\end{aligned}
$$

We notice that each of the twelve faculty members are modeled with a separate goal constraint. The accommodation for different teaching loads is easily incorporated into the model by simply changing the right-hand-side value of the corresponding equation.

\subsection{Required limited resources}

In this assignment problem, for each time-block, a maximum of four classrooms are available for scheduling. The constraints were developed by taking the decision variables listed in each column in Table 1 or Table 2 . There are a total of 17 goal constraints representing the available time-blocks. If there is no penalty for under achievement, the underachieving coefficient in the objective function could be ignored, which is the case in this assignment problem. In the current goal constraints and to represent the general case, both over- and under-achieving variables will be included.

It is clear that it is not necessary to repeat both definitions for every goal constraint in the model. Therefore, the notation from Table 2 will be used only. (13) provides the modeling of the number of classrooms per time-block for the first time-block:

$$
X_{1}+X_{13}+X_{34}+X_{49}+X_{73}+X_{85}+X_{94}+X_{151}+X_{160}+X_{172}+X_{187}+X_{199}+X_{211}+X_{223}+X_{229}+X_{250}+d_{44}^{-}-d_{44}^{+}=1
$$

\subsection{Faculty preferences for courses}

As mentioned earlier, each faculty member was asked to provide three preference ranks for each course they wished to teach. The faculty members were asked to show their desire to teach a certain course by identifying a row to contain that course, where row number one meant the course most desired to teach. All faculty members were required to identify three preference levels for each course they wished to teach. The model permits deviations from three preferences for each faculty member-course without any extra modeling efforts. We should also mention that the less ranks used by the faculty members, the fewer the number of decision variables and goal constraints required in the model. Since three different ranks were used, three goal constraints were necessary to model the faculty-to-course preferences.

(14) represents the modeling of the first rank. The right-hand-side value of 29 is obtained by counting the number of courses that received at least one rank of "one". We note that two courses did not receive votes for most preferred to teach. The courses that did not receive any first choice score were courses numbered 12 , and 27 . As a result, the right-hand-side will be equal to 29 , since there were 31 courses to assign. 


$$
\begin{aligned}
X_{1} & +X_{2}+X_{3}+X_{4}+X_{5}+X_{6}+X_{7}+X_{8}+X_{9}+X_{10}+X_{11}+X_{12}+X_{22}+X_{23}+X_{24}+X_{25}+X_{26}+X_{27}+X_{28}+X_{29}+X_{30}+X_{31} \\
& +X_{32}+X_{33}+X_{49}+X_{50}+X_{51}+X_{52}+X_{53}+X_{54}+X_{55}+X_{56}+X_{57}+X_{58}+X_{59}+X_{60}+X_{73}+X_{74}+X_{75}+X_{76}+X_{77} \\
& +X_{78}+X_{79}+X_{80}+X_{81}+X_{82}+X_{83}+X_{84}+X_{94}+X_{95}+X_{96}+X_{97}+X_{98}+X_{99}+X_{100}+X_{101}+X_{102}+X_{103}+X_{104} \\
& +X_{105}+X_{118}+X_{119}+X_{120}+X_{121}+X_{122}+X_{123}+X_{124}+X_{125}+X_{126}+X_{127}+X_{128}+X_{129}+X_{142}+X_{143}+X_{144} \\
& +X_{145}+X_{146}+X_{147}+X_{151}+X_{152}+X_{153}+X_{154}+X_{155}+X_{156}+X_{157}+X_{158}+X_{159}+X_{172}+X_{173}+X_{174}+X_{175}+X_{176} \\
& +X_{177}+X_{178}+X_{179}+X_{180}+X_{187}+X_{188}+X_{189}+X_{190}+X_{191}+X_{192}+X_{193}+X_{194}+X_{195}+X_{196}+X_{197}+X_{198}+X_{211} \\
& +X_{212}+X_{213}+X_{214}+X_{215}+X_{216}+X_{217}+X_{218}+X_{219}+X_{220}+X_{221}+X_{222}+X_{232}+X_{233}+X_{234}+X_{235}+X_{236}+X_{237} \\
& +X_{238}+X_{239}+X_{240}+X_{241}+X_{242}+X_{243}+d_{61}-d_{61}^{+}=29 .
\end{aligned}
$$

For the second and third course preferences, we can still use the same procedure to compute the righthand-side since the weights that we will assign to their associated deviation variables in the objective function will take care of the preference requirement. Another way to model the minimization of the second and third preferences is by setting the right-hand-side to equal zero.

\subsection{Faculty preferences for time}

The same logic that was used to satisfy faculty preferences for courses will be used to satisfy preferences for certain time-blocks. The right-hand-side will be obtained by counting the number of courses that had received at least one rank of "a" for a specified time-block. We should mention here that we still could assign the same right-hand-side value for the three equations that are necessary for the set of constraints since the weights that we will assign to the associated deviation variables in the objective function will take care of the preference requirements. (15) represents the preference for time constraint for the most preferred time-block.

$$
\begin{aligned}
X_{1} & +X_{4}+X_{7}+X_{10}+X_{13}+X_{16}+X_{21}+X_{22}+X_{25}+X_{28}+X_{31}+X_{34}+X_{37}+X_{40}+X_{43}+X_{46}+X_{49}+X_{52}+X_{57}+X_{58}+X_{61} \\
& +X_{64}+X_{68}+X_{72}+X_{74}+X_{76}+X_{80}+X_{82}+X_{85}+X_{90}+X_{91}+X_{95}+X_{97}+X_{100}+X_{103}+X_{106}+X_{109}+X_{113}+X_{117} \\
& +X_{118}+X_{121}+X_{125}+X_{128}+X_{130}+X_{134}+X_{136}+X_{139}+X_{142}+X_{145}+X_{148}+X_{151}+X_{154}+X_{157}+X_{160}+X_{163}+X_{166} \\
& +X_{169}+X_{172}+X_{175}+X_{178}+X_{181}+X_{184}+X_{187}+X_{190}+X_{193}+X_{196}+X_{199}+X_{202}+X_{205}+X_{208}+X_{211}+X_{214}+X_{217} \\
& +X_{220}+X_{223}+X_{226}+X_{229}+X_{232}+X_{237}+X_{238}+X_{241}+X_{244}+X_{247}+X_{250}+d_{64}-d_{64}^{+}=31 .
\end{aligned}
$$

\subsection{System constraints}

In order to ensure that only one ranking for each course is selected, we need a system of constraints to prevent splitting of the decision variables. For example, from Table 1 , the variables $X_{1 \mathrm{a}}, X_{1 \mathrm{~b}}$, and $X_{1 \mathrm{c}}$ represent the same course but given different time preferences. Meanwhile, from Table 2, $X_{1}, X_{2}$, and $X_{3}$ represent the same course. The required system constraints for the course numbered "1" is given in (16):

$$
X_{1}+X_{2}+X_{3} \leq 1
$$

We also need system constraints to ensure that for a certain faculty member, only one course is assigned during a certain time-block. For example, for faculty number one during the first time-block, we notice that two courses appear (courses one and five). As a result, we need an equation to ensure that only one of the two courses will be picked for teaching by faculty number one during time-block number one. (17) represents the described situation. Moreover, we note that some faculty members have picked more than two courses to be taught during a certain time-block (for example, faculty number six from 4:30 to 6:00 on Saturdays, Mondays, and Wednesdays):

$$
X_{123}+X_{133}+X_{137} \leq 1 \text {. }
$$

By a simple counting procedure, we note that a total of 83 system constraints of the sort mentioned are needed. We also note that an inequality sign is used since most of the decision variables will equal zero in the final solution. 


\subsection{The objective function}

The resulting objective function for this assignment problem is provided in (18). The weights used for course and time priorities are simply the inverse ordering of the three ranks established and assigned by the faculty.

The first part of this equation will have a total of 62 deviation variables ( 31 positive deviation variables and 31 negative deviation variables). The second part will have a total of 24 deviation variables, the third part will have a total of 34 deviational variables, the fourth and the fifth parts will have only 6 deviation variables each:

$$
\begin{aligned}
\operatorname{minimize} Z & =P_{1} \sum_{j=1}^{31}\left(d_{j}^{s-}+d_{j}^{s+}\right)+P_{2} \sum_{i=32}^{43}\left(d_{i}^{t^{-}}+d_{i}^{l+}\right) P_{3} \sum_{k=44}^{60}\left(d_{k}^{c^{-}}+d_{k}^{c+}\right)+P_{4} \sum_{z_{1}=61}^{63} w_{z_{1}}\left(d_{z_{1}}^{g^{-}}+d_{z_{1}}^{g^{+}}\right) \\
& +P_{5} \sum_{z_{2}=64}^{66} w_{z_{2}}\left(d_{z_{2}}^{-}+d_{z_{2}}^{+}\right) .
\end{aligned}
$$

\section{RESULTSAND DISCUSSION}

The formulated problem consisted of 252 decision variables, 66 goal constraints, 84 system constraints to prevent variable splitting, and 83 system constraints to guarantee that only one course is scheduled for each faculty member during certain time-blocks. The problem was solved using a modified simplex program for goal programming on the PC. The assignment problem required less than half a minutes of execution time on a Pentium $90 \mathrm{MHz}$ personal computer with $4 \mathrm{MB}$ RAM. The department chairman was asked to set the priorities for each of the goals. The priorities set were as follows $\left(P_{1}>>>P_{2}>>>P_{5}>>>P_{4}>>>P_{3}\right)$ :

$\begin{array}{ll}\text { First priority }\left(P_{1}\right): & \text { assign all courses; } \\ \text { Second priority }\left(P_{2}\right): & \text { satisfy all teaching loads; } \\ \text { Third priority }\left(P_{5}\right): & \text { satisfy faculty-course priorities; } \\ \text { Fourth priority }\left(P_{4}\right): & \text { satisfy course-time priorities; and } \\ \text { Fifth priority }\left(P_{3}\right): & \text { satisfy available space for each time-block. }\end{array}$

In the solution, the first departmental priority of offering all of the desired semester courses was fully achieved. The second priority of meeting teaching load requirement was also fully achieved. We should recall that there were enough faculty-hours available to cover the required courses. As a result, no problem was faced with the second priority (there were 31 possible faculty hours (course) available for covering 31 courses). The flexibility of using goal programming will allow us to model a schedule where the available teaching loads is less than the required course offerings. In such a situation, deviations result to mean that the department is forced to acquire the services of visiting professor. It is also possible in this situation to increase the teaching load of certain faculty to accommodate the shortage.

The third and fourth priorities of satisfying faculty-course and course-time preferences were not fully achieved. The weighted faculty preferences priority for specific course assignment and for specific timeblocks were only minimized in the resulting solution, since the faculty preference rankings were conflicting by their very nature. We should also recall at this point that the model attempts to combine the two preferences of course and time. The objective is, of course, to minimize the overall deviations from goals. As a result, a tradeoff is made to produce a mixture of preference combinations; while some faculty do not get their course preferences, other faculty members do not get their time preferences for courses. At the same time, some faculty members get both their preferences for courses and time satisfied.

The final objective of scheduling certain number of courses during a time-block is also achieved except for the fourth time-block, (11:00 to 12:00 on Saturdays, Mondays and Wednesdays), in which five courses are scheduled. The fact that the department chairperson assigned the lowest priority to the goal concerning availability of classes means that other means are available to acquire a class from other colleges for that extra course. We should also mention here that the model easily could accommodate other departmental objectives mentioned by Badri [3]. For example, certain courses might be desired to be assigned to certain faculty. In this case, we could introduce system variables in the form of $X_{i j k}$ to equal one, meaning that faculty $(i)$ to teach course $(j)$ during time-block $(k)$. Badri also used other goals such as limiting the number of night courses to a certain number (two per faculty for example). In the current model, this goal could be accommodated by setting the right-hand-side of certain equations to the required number. 
Masood A. Badri et al.

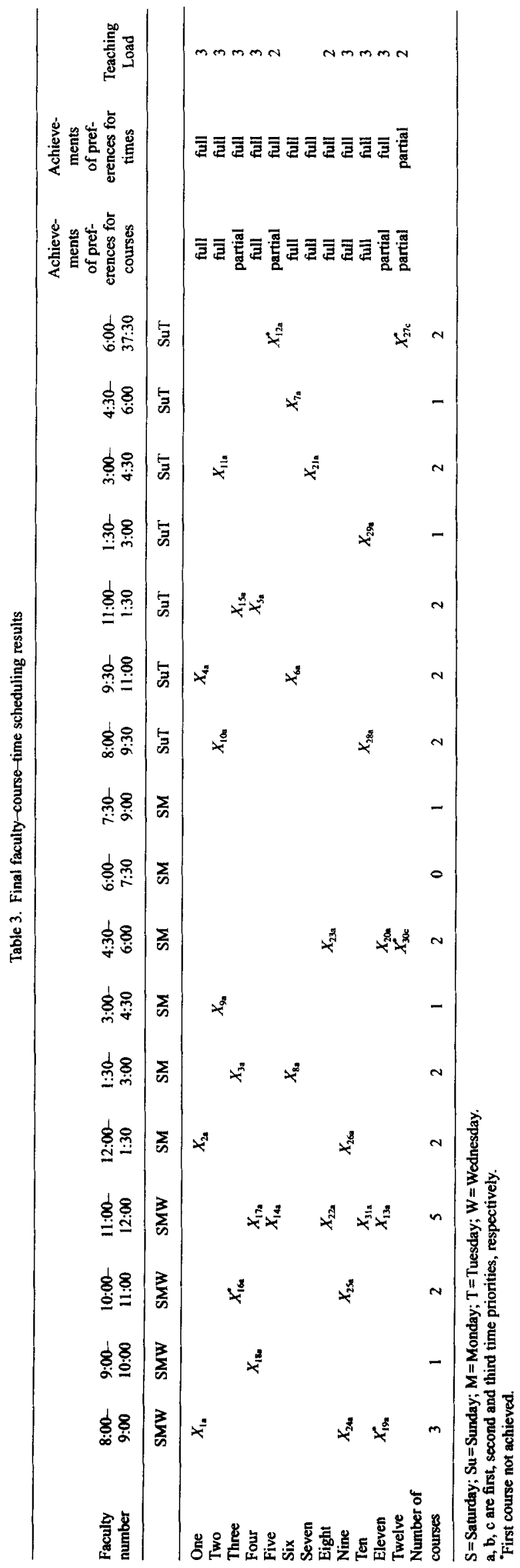


The resulting solution in Table 3 is appealing to both department chairperson and the involved faculty in light of the fact that 24 first preferences for faculty-course assignments was made (constituting $86 \%$ achievement). We should also recall that two courses, numbers 12 and 27 , received ranks as second choices only; as a result, and by their nature, they were not given optimum assignments. It is very important in this regard to mention that it is extremely necessary for each faculty member to provide as many alternatives to course or time preferences. That way, the model will have more flexibility to provide the required assignment. Of the four faculty-course assignments that were not first preferences, three received assignments to which they had given the second highest rank, while one assignment was ranked third by the involved faculty. In the solution, it is also obvious that most of the decision variables will equal zero, meaning that no assignment was made.

\section{CONCLUSION}

We have described a model that can be used to schedule courses in departments of colleges and universities. The model is built through a one-stage process in which faculty-course assignments, and course-time assignments are made at the same time simultaneously. The model uses decision variables that represent schedules (assignments). The application illustrates how the faculty assignment problem could be structured into relatively small model (i.e. relative to the models in prior research), requiring little time and expertise, and be processed by available staff support (a student or a secretary).

The multi-objective structure has enabled the model to capture the dynamic aspects of the problem and serve as a convenient and suitable course scheduling decision support system.

The core of the procedure is formed by a matrix where three rows are provided for each faculty member denoting three preferences respectively for teaching certain courses. The matrix also contains elements indicating faculty preferences for teaching those courses during certain time-blocks. Letters (a, $\mathrm{b}$, and $\mathrm{c}$ ) were used to provide preferences for teaching during certain time-blocks.

The proposed model permitted the use of quite a few criteria to be included in the modeling process. Additional goal constraints and priorities can be utilized to reflect other desired decision criteria. The current research paper takes advantage of existing research and extends them to present a more comprehensive model characterized by simplicity and ease. The procedure described by Badri [3] is further enhanced by allowing the model to deal with preferences for courses and times simultaneously rather than considering them in two stages.

Acknowledgements - The authors wish to thank two anonymous referees for their careful reviewing and helpful comments.

\section{REFERENCES}

1. Tillet, P., An operations research approach to the assignment of teachers to courses. Socio-Economic Planning Sciences, 1975 , 9, 101-104.

2. Schniederjans, M. and Kim, G., A goal programming model to optimize departmental preference in course assignments. Computers and Operations Research, 1987, 14, 2 87-96.

3. Badri, M., A two-stage multi criteria model for scheduling faculty-course-time assignment. European Journal of Operational Research, 1996, 96, 16-28.

4. Harwood, G. and Lawless, R., Optimizing organizational goals in assigning faculty teaching schedules. Decision Sciences, $1975,6,513-524$.

5. Franz, L., Lee, S. and Van Horn, J., An adaptive decision support system for academic recourse planning. Decision Science, $1981,12,276-293$.

6. Joiner, C., Academic planning through the goal programming model. Interfaces, 1980, 10, 86-92.

7. Lee, S. and Clayton, E., A goal programming model for academic recourse planning. Management Science, 1972, 18, $390-408$.

8. Smith, L., Planning models for budgeting teaching resources. Omega, 1978, 6, 83-88.

9. Brislaw, J., A linear programming solution to the faculty assignment problem. Socio-Economic Planning Science, 1976, 10, 227-230.

10. McClure, R. and Wells, C., A mathematical programming model for faculty course assignment. Decision Science, 1984, 15, 409-420.

11. Shih, W. and Sullivan, J., Dynamic course scheduling for college faculty via zero-one programming. Decision Sciences, 1977 , $8,711-721$.

12. Andrew, G. and Collins, R., Matching faculty to courses. College and University, 1971, 46, 83-89.

13. Dyer, J. and Mulvey, J., An integrated optimization/information system for academic department planning. Management Science, 1976, 22, 1332-1341.

14. Kang, L., A logic approach to the resolution of constraints in time tabling. European Journal of Operational Research, 1992, 61, 3 306-317.

15. Mathaisel, D. and Comm, C., Course and classroom scheduling: An interactive computer graphics approach. Journal of Systems and Software, 1991, 15, 2 149-157.

16. Dinkel, J., Mote, J. and Venkataramanan, M., An efficient decision support system for academic course scheduling. Operations Research, 1989, 37, $6853-864$. 

17. Kassicieh, S., Burleson, D. and Lievano, R., Design and implementation of a decision support system for academic scheduling.
Information and Management, 1986, 11, $257-64$.

18. Anderson, D., Sweeney, D. and Williams, T., An Introduction to Management Science: Quantitative Approaches to Decision Making, 7th ed. West Publishing, Minneapolis, St. Paul, 1994.

19. Lee, S., Goal Programming for Decision Analysis. Auberback Publishers, Philadelphia, 1972. 20. Lee, S. and Schniederjans, M., Multi criteria assignment problem: A goal programming approach. Interfaces, 1983, 13,
$75-81$.

21. Schniederjans, M., Kwak, N. and Helmer, C., An application of goal programming to resolve a site location problem. Interfaces, 1982, 12, 65-72. 